\title{
AUTHOR GUIDELINES
}

\section{The Editorial Process}

PJN is an international peer - reviewed, professional journal for nurses. Welcomes articles on all aspects. The manuscripts will be reviewed for possible publication with the understanding that they are being submitted to one journal at a time and have not been published, simultaneously submitted or already accepted for publication elsewhere.

The Editors review all submitted manuscripts initially. Manuscripts with insufficient originality, serious scientific and technical flaws or lack of a significant message are rejected. All manuscripts received are duly acknowledged. Manuscripts are sent to two or more expert and international peer reviewers without revealing the identity of the contributors to the reviewers. Each manuscript is also assigned to a member of the editorial team, who based on the comments from the reviewers takes a final decision on the manuscript. The contributors will be informed about the reviewer's comments and acceptance/ rejection of manuscript.

\section{Types of Manuscripts and Limits}

- Original articles: Randomized controlled trials, intervention studied, studies of screening, outcome studies, case-control series, and surveys with high response rate. Up to 3000 words excluding adequate references and abstract.

- Review articles (including for Ethics forum, Education forum, Health related science, EMedicine, E-Nursing etc.): Systemic critical assessments of literature and data sources. Up to 2000 words excluding with adequate references. Research articles critical review, advertisement, functions celebrated, puzzles and innovation related items.

- Case reports: new/ interesting/ very rare cases can be reported. Cases with clinical significance or implications will be given priority. However, mere reporting of a rare case may not be considered. Up to 1000 words excluding references and abstract and up to 05 references.

\section{Presentation and Submission of Article}

- Double spacing, TIMES NEW ROMAN

- Margins $2.5 \mathrm{~cm}$ from all four sides

- Title contains all the desired information

- Abstract page contains the full title of the manuscript

- Introduction of 75 words.

- Headings in title case ( not ALL CAPITALS)

- The references cited in the text \& should follow Vancouver both for journals \& look reference.

- Send the final article file without 'Track changes' \& send hard \& soft copy for the articles. 


\title{
Language and grammar
}

- Write the full term for each abbreviation at its first use in the title, abstract, keywords and text separately unless it is a standard unit of measure.

- Numerals at the beginning of the sentence spelt out.

- Check the manuscript for spelling, grammar and punctuation errors

\section{Tables and Figures}

- No repetition of data in tables and graphs and in text

- Actual numbers from which graphs drawn, provided

- Figures necessary and of good quality ( color)

- Table and figure numbers in Arabic letters (not Roman)

- Write the full term for each abbreviation used in the table as a footnote.

Article from Graduate and Post Graduate will also be accepted. Please follow the same format for research articles.

- Title

- Abstract

- Introduction - Objectives/Need for the study with justification

- Materials and methods-includes Research design, approach, setting, population, sample size \& techniques

- Major Findings with Tables and Figures for objectives

- References

Author information in a separate page as follows:

- Name, Academic degree, Designation

- Name of the institution

- Address for correspondence including phone number and Email Id.

All articles will be peer reviewed. The Editorial board and chief editor will decide on suitabililty of publication of a material which is final. The last minute submission of article will not be considered for current issue.

\author{
Correspondence Address: \\ Prof. Dr. S. Kamalam \\ Chief Editor, Pondicherry Journal of Nursing \\ Principal, Kasturba Gandhi Nursing College, MGMC\&RI Campus, Pillaiyarkuppam, \\ Puducherry - 607402.
}

Ph: 0413-2615449 (Ext.511), 2615809, Fax: 0413-2615457

E-mail-kgncpjn@yahoo.com 